\title{
CHARACTERIZING VOLATILES AND ATTRACTIVENESS OF FIVE BRASSICACEOUS PLANTS WITH POTENTIAL FOR A 'PUSH-PULL' STRATEGY TOWARD THE CABBAGE ROOT FLY, Delia radicum
}

\author{
ALAN KERGUNTEUIL , SÉBASTIEN DUGRAVOT , HOLGER DANNER , \\ NICOLE M. VAN DAM ${ }^{3,4}$, ANNE MARIE CORTESERO
}

1. Université de Rennes 1, UMR 1349 IGEPP, F-35000 Rennes, France.

2. UEB. Université Européenne de Bretagne, France.

3. Department of Molecular Interactions Ecology, Institute for Water and Wetland Research (IWWR), Radboud University, Heyendaalseweg 135, 6525 AJ Nijmegen, The Netherlands.

4. current address: German Centre for Integrative Biodiversity Research (iDiv) Halle-JenaLeipzig, Deutscher Platz 5e, D-04103 Leipzig, Germany/Institute of Ecology, Friedrich

Schiller University Jena, Dornburger-Str. 159, 07743 Jena, Germany

* Corresponding author : ker.alan@yahoo.fr

\begin{abstract}
Volatile Organic Compounds (VOCs) released by plants are involved in different orientation processes of herbivorous insects and consequently play a crucial role in their reproductive success. In the context of developing new strategies for crop protection, several studies have previously demonstrated the possibility to limit insect density on crops using either host or non-host plants releasing attractive or repellent VOCs respectively. The cabbage root fly, Delia radicum, is an important pest of brassicaceous crops for which control methods have to be implemented. Several studies have shown that plant odours influence cabbage root fly behavior but only few VOCs have been identified so far. The present study aims at selecting both plants and olfactory stimuli that could be used in the development of a "pushpull" strategy against the cabbage root fly. Our olfactometer results revealed that plants belonging to the same family, even to the same species may exhibit different levels of attractiveness toward $D$. radicum. Plants that were determined as attractive through our behavioral observations were characterized by high release rates of distinct terpenes such as linalool, $\beta$-caryophyllene, humulene and $\alpha$-farnesene. This study represents a first step to identify both attractive plants of agronomic interest and additional volatiles that could be used in the context of trap crops to protect broccoli fields against the cabbage root fly.
\end{abstract}

Key Words / Plant attractiveness, Volatile organic compounds, Olfactometer, Terpenes, "Push-Pull" strategy, Delia radicum. 


\section{INTRODUCTION}

Plant secondary metabolites are important sources of information in several steps during the life cycle of insect herbivores and may account for the selection of feeding sites, shelter, mates and host plants (Schoonhoven et al. 2005; Visser 1986). Although short range visual cues and chemo-contact stimuli originating from plants have been shown to play a role, long range cues conveyed by plant odours have the advantage that they allow insects to optimize behavioural responses over large distances (Schoonhoven et al. 2005). The complex blends of Volatile Organic Compounds (VOCs) released by plants may contain more than 200 compounds, however, only a subset of these volatiles are detected by phytophagous insects (Bruce et al. 2005; Bruce and Pickett 2011). Plant derived VOCs serve various ecological functions in plant-herbivore interactions. Herbivores can be either attracted or repelled by plant odours according to the suitability of plants and insect experiences (Visser 1986; Wang et al. 2008). In addition to host plant localization, VOCs are used by insects to estimate resource quality (Bengtsson et al. 2001; Magalhães et al. 2012; Piesik et al. 2013). In a multitrophic context, plant odours can also inform herbivores about the presence of competitors or natural enemies (Dicke and Baldwin 2010; Sabelis et al. 2001). This diversity in ecological functions of VOCs offers many starting points for integrated pest management strategies to manipulate the communication between plants, phytophagous insects and their natural enemies. In an agricultural context these semiochemicals can be practically applied to reduce the use of common pesticides in integrated pest management strategies (Shrivastava et al. 2010; Szendrei and Rodriguez-Saona 2010).

Recently, several studies have demonstrated the possibility to limit herbivore densities on crops with host or non-host co-cultural plants releasing certain VOCs (Cook et al. 2007 b; Togni et al. 2010; Zhang et al. 2013). The "push-pull" strategy combines negative and positive stimuli to both deter pests from target crop plantations and attract herbivores into trap crops surrounding the plantations (Cook et al. 2007 a; Pickett et al. 2014). Today, this strategy has been adopted by nearly 70,000 smallholder farmers to protect sub-saharian cereal crops against stem borers (Khan et al. 2014). Successful control of stem borer populations is achieved by its response to VOCs released by "push" and "pull" plants, i.e. the repelling intercrop and the trap crop (Khan et al. 2010). Understanding insect responses to complex VOCs mixtures emitted by host and non-host plants is essential for the development of new environmentally sound crop protection strategies (Pickett et al. 2012). 
The main purpose of the present study is to contribute to the development of a "pushpull" strategy against the cabbage root fly, Delia radicum (Diptera: Anthomyiidae). The cabbage root fly is a worldwide oligophagous pest specialized on brassicaceous plants. Females lay eggs on plant stems, and larva develop by feeding on roots. This pest can cause severe damage in different brassicaceous crops such as broccoli, turnip, rutabaga, cabbage or cauliflower. Cabbage root fly infestations may cause a yield loss of up to $90 \%$ in fields not treated with pesticides (Finch 1989). The necessary reduction of the use of insecticides requires the development of alternative crop protection methods. The behavioural sequence that leads to oviposition of flies on a plant involves several cues. The role of proximate stimuli (e.g. visual cues and chemo-contact stimuli) has been well documented (de Jong et al. 2000; Finch and Collier 2000; Griffiths et al. 2001; Roessingh and Städler 1990; Tuttle et al. 1988) but only a few olfactory stimuli have been identified so far, and the distance at which they are used by D. radicum remains unclear (Finch and Skinner 1982). Among host plant volatiles, allylisothiocyanate was shown to be involved in the long distance orientation of flies (Hawkes and Coaker 1979; Wallbank and Wheathley 1979) while dimethyl disulfide was shown to reduce oviposition rates (Ferry et al. 2009). Also, salicylaldehyde, a common volatile emitted by various plant species, has been shown to repel flies and reduce oviposition (den Ouden et al. 1997). The identification of new behaviourally active compounds could help developing control strategies based on pest behavior manipulations.

In the present paper, we aim at selecting both plants and olfactory stimuli that could be used in the development of a "push-pull" strategy against the cabbage root fly either with trap crops or synthetic VOCs. First, we tested the attractiveness of five undamaged brassicaceous plants belonging to the host plant range of the fly through olfactometer bioassays. Based on previous studies, three species of agricultural interest were retained : in comparison to cultivated broccoli (Brassica oleracea), the white mustard (Sinapis alba) has been shown to be partially resistant to the cabbage root fly (Jyoti et al. 2001) while Chinese cabbage (B. rapa pekinensis) harbours high levels of infestation among brassicaceous species (Rousse et al. 2003). In addition, two experimental genotypes of oilseed rape (B. napus 'Yudal' and 'Darmor-bzh') were also tested because of their diverging resistances to different bioaggressors, with 'Yudal' being generally less resistant to pathogen attacks (Delourme et al. 2008; Jestin et al. 2011; Manzanares-Dauleux et al. 2000). Based on previous studies, carried out under field conditions (Kergunteuil 2013), we selected three species of agriculturat interest (Brassica oleraceae, B. rapa pekinensis, Sinapis alba) and two experimentat 
genotypes of oilseed rape (B. napus 'Yudal' and 'Darmor-bzh'). The two genotypes of $B$. napus were chosen because of their diverging resistances to different bio-aggressors, with 'Yudal' being generally less resistant to pathogen attacks (Delourme et al. 2008; Jestin et al. 2011; Manzanares Dauleux et al. 2000). We subsequently characterized the VOC blends emitted by these five brassicaceous plants in order to identify compounds that could be involved in the long distance orientation of the fly and could be used to attract flies towards trap crops.

\section{MATERIALS AND METHODS}

\section{Plants}

Experiments were carried out with five different plants: broccoli (Brassica oleracea), Chinese cabbage (B. rapa pekinensis), white mustard (Sinapis alba) and two genotypes of oilseed rape (B. napus 'Yudal' and 'Darmor-bzh'). Single seeds were directly sown in a 9x 9x $11 \mathrm{~cm}$ pot filled with a peat : sand mixture soil (Lentse Potgrond $\mathrm{n}^{\circ} 2$, Horticoop, Bleiswijk, The Netherlands) containing nutrients with $2 \mathrm{~cm}$ of clean river sand on top. Plants were grown in a glasshouse (Nijmegen, Netherlands) at $16 \mathrm{~h}: 8 \mathrm{~h}(\mathrm{~L}: \mathrm{D}), 21^{\circ} \mathrm{C}: 19.5^{\circ} \mathrm{C}(\mathrm{L}: \mathrm{D})$ and watered twice a week. Daylight was supplemented with sodium lamps (600 W) when natural light was lower than 13500 lux. Plants used for experiments were 5 weeks old, corresponding to 7-8 leaves for broccoli and oilseed rape, and 10-12 leaves for Chinese cabbage. The white mustard plants grew faster and were used when they were 3 weeks old and had 7-8 leaves. The plants had approximately an equal leaf surface area when tested. All plants used for VOC collections and behavioural experiments grew under the same conditions and were in the vegetative stage when sampled.

\section{Behavioural Experiments}

Insects. Females of Delia radicum used for the experiments originated from a colony started in July 2012 from field collected flies (Le Rheu, Brittany, France, $48^{\circ} 07^{\prime} 16^{\prime}$ ' N, $01^{\circ}$ 47 '41' W). The fly colony was fed with a milk powder: yeast: sugar (1:1:1) mixture and kept in a climatic chamber at $16 \mathrm{~h}: 8 \mathrm{~h}(\mathrm{~L}: \mathrm{D}), 21 \pm 2^{\circ} \mathrm{C}$ and $60 \pm 10 \% \mathrm{RH}$. Rearing conditions were adapted from Neveu Bernard-Griffiths (1998). Pupae from this colony were sent weekly to the Netherlands, where all the experiments took place and kept in a cage with water and food under similar conditions. Three days after emergence, females were considered as fertilized and were used for experiments until they were 12 days old. All tests were conducted in a room maintained at $21 \pm 2{ }^{\circ} \mathrm{C}$ and $60 \pm 10 \% \mathrm{RH}$ with artificial lights. To acclimatize the flies 
before the experiments, they were isolated and placed in the test room at least $15 \mathrm{~min}$ before the assays started.

Olfactometer Tests. Behavioural responses of D. radicum towards controls (i.e. pure air) or odours emitted by the five test plants were monitored using a tubular olfactometer (60 x $5 \mathrm{~cm} \mathrm{ID)} \mathrm{artificially} \mathrm{divided} \mathrm{into} \mathrm{three} \mathrm{sections} \mathrm{of} 20 \mathrm{~cm}$. In a tubular olfactometer such as the one used here, time spent by females in the different sections provides interesting behavioural information: while time spent in the first section corresponds to latency or absence of response, time spent in the last section reflects attractiveness. Light was supplied by four neon lights (Philips, Master TL-D Reflex 36W/ 840) placed above the tube. The airflow was provided by a bottle of normal compressed air (N:0 / 80:20) humidified by leading the air through a washing bottle filled with water before reaching a plant enclosed in a PET oven bag (polyethylene terephthalate, $25 \times 40 \mathrm{~cm}$, Dumil, ITH Complast BV, The Netherlands). Airflow in the olfactometer was maintained at $400 \mathrm{ml} \cdot \mathrm{min}^{-1}$. All connections were made with PTFE (polytetrafluorethylene) tubing. Females were placed individually in the tube and their behaviour was recorded during 10 minutes. The tubular olfactometer was placed in a white box in order to avoid any visual stimuli from the plant. For each plant tested, 3 or 4 individual plants and 29 to 38 females were used (between 5 and 16 females per plant). Olfactometer tests were carried out over a period of three consecutive weeks. The testing of the different plants (including the control with pure air) were randomized over this period. The entire device was washed with ethanol, dried and purged during fifteen minutes with clean air before starting new observations.

\section{VOC Analyses}

Volatile Collection. VOCs were collected in a climate chamber (Snijder-scientific, Tilburg, The Netherlands) maintained at $21^{\circ} \mathrm{C}$ and $50 \% \mathrm{RH}$ using a "push-pull" system as described by Tholl et al. (2006). The shoots were enclosed in PET oven bags $(25 \mathrm{x} 40 \mathrm{~cm}$; Toppits, Germany) connected with PTFE tubing to two pumps. A continuous air stream into the bag was generated with the first pump at $9 \mathrm{~L} \cdot \mathrm{h}^{-1}$. The airflow passed an activated charcoal filter before reaching the enclosed plants while a second pump maintained the outgoing airflow at $8 \mathrm{~L} . \mathrm{h}^{-1}$. Volatiles were trapped during $24 \mathrm{~h}$ on filters packed with $30 \mathrm{mg}$ of Porapak Q (60:80 mesh). Collection tubes were cleaned with $500 \mu 1$ of GC-grade dichloromethane and dried before use. One plant of each of the five plant species was sampled on the same day. Volatiles were collected from twelve individual plants for each test plants, except for the oilseed rape 'Yudal' with 11 replicates. 
Gas Chromatography and VOC Identification. Collected volatiles were eluted with $150 \mu \mathrm{l}$ dichloromethane containing $5 \mathrm{ng} \cdot \mu^{-1}$ nonyl acetate as an internal standard. The samples were stored at $-20^{\circ} \mathrm{C}$ until $\mathrm{GC} / \mathrm{MS}$ analysis. Qualitative and relative quantitative determination of VOCs was conducted using an Agilent 7890 Series gas chromatograph (injector temp.: $250^{\circ} \mathrm{C}$, injection volume: $1 \mu \mathrm{l}$, splitless mode) coupled to a JEOL accurate mass TOF instrument (JMS T100-GCV, interface temp.: $250{ }^{\circ} \mathrm{C}$; ion chamber temp.: $200{ }^{\circ} \mathrm{C}$, ionizing voltage: $70 \mathrm{eV}$ ) recording spectra every $0.4 \mathrm{~s}$ in the range from 30-500 amu. VOCs were separated with a DB-5MS column (Agilent, Santa Clara, CA, USA, $30 \mathrm{~m}, 0.25 \mathrm{~mm}$, $0.25 \mu \mathrm{m})$ using $\mathrm{He}$ as the carrier gas. The oven temperature was programed as follows: $40^{\circ} \mathrm{C}$ raised to $95^{\circ} \mathrm{C}$ at $3^{\circ} \mathrm{C} \cdot \mathrm{min}^{-1}$, then raised to $165^{\circ} \mathrm{C}$ at $2^{\circ} \mathrm{C} \cdot \mathrm{min}^{-1}$ and finally to $250^{\circ} \mathrm{C}$ at $15^{\circ} \mathrm{C} \cdot \mathrm{min}^{-1}$, after which the temperature was held constant for $15 \mathrm{~min}$. After deconvolution with AMDIS (version 2.7.1), compounds were identified by comparison of retention times and mass spectra to those of authentic standards ( $\alpha$-pinene, hexyl acetate, limonene, linalool) obtained from Sigma (St. Louis, MO, USA), or tentatively identified by reference spectra given in the National Institute of Standards and Technology libraries (2011), corresponding retention indices in the literature (RIs obtained on DB-5 column - for reference see Table 1) and comparison of measured exact masses with calculated masses.

Data Analysis of Chromatographic Peaks. The centroided data from GC/MS were processed using the Bioconductor package XCMS (peak detection : 'CentWave' algorithm ; retention time correction : 'Symmetric' method) ) implemented in the R software (Smith et al. 2006).- - As different metabolites may incidentally co-elute, the Bioconductor package CAMERA was used to group ion species according to their parent compound (Kuhl et al. 2012). Finally, a data matrix containing mass to charge features $(\mathrm{m} / \mathrm{z})$, retention times, mass signal intensities, and peak correlation groups (i.e. pseudo-spectra corresponding to ion chromatograms of the individual compounds) was generated.- For each pseudo-spectrum, the $\mathrm{m} / \mathrm{z}$ signal representing the base peak of the spectrum was used as quantifier ion. Areas were normalized to the peak area of the internal standard (quantifier ion: $126 \mathrm{~m} / \mathrm{z}$ ) in order to avoid variations in detector sensitivity and variation due to peak broadening. Depending on the selected quantifier ion this approach allows to determine and compare relative amounts of the same compound released by plants of different species.

\section{Statistical Analyses}

All statistical tests were performed using the software R, version 3.1.0 (R Core Team, 2014). The mean time spent in each section of the olfactometer was assessed with a 
generalized linear model (GLM) (package 'lme4': Bates et al. 2013). The goodness-of-fit of each model tested was estimated by graphical observations of (i) the model residuals plotted against the fitted values (ii) the quantile randomized residuals plotted against the normal distribution quantiles. A GLM with 'quasi-poisson' distribution (linking function: 'log') was finally retained to take account of over-dispersion. Mean time differences were estimated by contrasts methods applied to GLM (package ‘doBy’: Højsgaard et al. 2013).

Differences in relative amounts of VOCs between the five plants were analysed using non-parametric tests: Kruskal-Wallis one-way analysis and pairwise Wilcoxon rank sum test ( $P$ were adjusted with the Benjamini and Hochberg correction: Benjamini and Hochberg, 1995). A principal component analysis (packages 'ade4': Dray and Dufour 2007) was performed from the whole set of relative amounts of VOCs identified and presented in Table 1.

\section{RESULTS}

Behavioural Experiments. In pure air, i.e. without any plant volatiles, female flies mostly remained in the first section of the olfactometer during the test period (about 7 minutes; FIG.1). Two species elicited a response pattern similar to clean air. Flies exposed to white mustard S. alba and oilseed rape B. napus 'Darmor-bzh' also spent most of their times in the first twenty centimetres of the olfactometer (GLM, contrasts method, respectively: $t=-$ 5.66, $d f=87, P<0.001 ; t=-2.74 d f=111, P<0.01)$. However, B. napus 'Darmor-bzh' triggered a slight upwind response as flies spent significantly more time in section 3 than in pure air (FIG.1). The time spent in the first section of the olfactometer was significantly shorter for the three other plants: flies exposed to B. oleracea, B. napus 'Yudal' and B. rapa pekinensis spent only two minutes in the first twenty centimetres of the olfactometer. Volatiles from these three species triggered an upwind movement, and flies quickly progressed towards the upwind end of the olfactometer. As shown in FIG. 1, two patterns of movement could be identified for these three attractive species. Females exposed to broccoli volatiles spent more time in section 2 than in the proximate section 1 or in the ultimate section 3 (GLM, contrasts method, respectively: $t=3.00, d f=87, P<0.01 ; t=-2.60, d f=87, P=$ 0.01). Females exposed to Chinese cabbage and 'Yudal' oilseed rape genotype volatiles spent more time in section 3 than in the others (GLM, contrasts method, respectively: $t=-5.08, d f=$ $87, P<0.001 ; t=-3.21, d f=84, P=0.001)$. 
VOC Analyses. Table 1 reports the 15 compounds, mainly terpenes, found across the five test plants. All compounds identified in the present study have been previously reported in the literature as being emitted by brassicaceous plants, except $\alpha$-copaene which is released by other plant families (Abel et al. 2009; Gols et al. 2012; Ibrahim et al. 2005; Pierre et al. 2011; Schiestl 2010; Tollsten and Bergström 1989; van Dam et al. 2010). The overall difference between VOCs profiles was explored through a principal component analysis (PCA). The two PCA axis explained $32 \%$ and $14 \%$ of the variance, respectively (FIG. 2a). Chemical differences in volatile blends were pronounced both between the four species and, more importantly, between the two genotypes of B. napus. The differences between the two genotypes of $B$. napus were pronounced on both principal axes of the PCA. Figure $2 b$ indicates that plant volatile emission from B. napus 'Darmor-bzh' genotype was characterized by $\alpha$-thujene (2) and $\beta$-elemene (12) while the VOC profile of the 'Yudal' genotype was characterized by 1 -hexanol (1), $\alpha$-copaene (11), $\beta$-caryophyllene (13), and humulene (14). Brassica oleracea was slightly separated from the other plants through the emission of $\alpha$ phellandrene (4), 1,8-cineole (8) and $\alpha$-farnesene (15). The four terpenes emitted by $S$. alba were also released by B. rapa pekinensis and both $\alpha$-pinene (3) and limonene (7) were emitted in similar amounts by these two species, resulting in a relatively close projection on both axes of the PCA despite strong differences in the attractiveness towards cabbage root flies. Comparing the emission of single compounds between species, the VOC profiles released by the three attractive plants were characterized by high release rates of four volatiles : linalool (9) for B. rapa pekinensis, $\beta$-caryophyllene (13) and humulene (14) for B. napus 'Yudal', and $\alpha$-farnesene (15) for B. oleraceae. Only one compound, limonene (7), was emitted in the same amounts by all five species tested (Table 1).

\section{DISCUSSION}

Previous studies have shown that cabbage root fly orientation is partially based on plant VOCs (Hawkes and Coaker 1979; Wallbank and Wheathley 1979) although the role of contact cues and visual stimuli in the choice for egg-deposition is also important (Finch and Collier 2000). The present study reveals important differences in the attraction of the cabbage root fly, a phytophagous insect specializing on brassicaceous plants, among plants belonging to the same family as well as between plant genotypes of the same species. In addition, chemical analyses allow to identify VOCs that may be involved in different plant 
attractiveness. Our results provide insights into the selection of plants and semiochemicals with potential for pest control strategies based on behavioural manipulation of $D$. radicum.

In comparison to pure air, three levels of attractiveness can be distinguished for the five species tested in our olfactometer bioassay. The attractiveness of $S$. alba and B. napus 'Darmor-bzh' is limited despite the slight attraction observed for the latter in section 3 of the olfactometer, probably due to common plant odours. The three other species are more stimulatory: B. oleraceae shows an intermediate level of attraction while B. napus 'Yudal' and B. rapa pekinensis are most attractive for females.

Combining behavioural observations with chemical analyses indicates that the three attractive species are characterized by relatively high release rates of distinct terpenes such as linalool (9) for B. rapa pekinensis, $\beta$-caryophyllene (13) and humulene (14) for B. napus 'Yudal' and $\alpha$-farnesene (15) for B. oleracea. In an ecological context, high amounts of VOCs may increase plant apparency to natural enemies but also to phytophagous insects, sometimes resulting in an overall increase of plant infestation (Halitschke et al. 2008). Parallel experiments that we conducted in the field with the same brassicaceous plants support this hypothesis: the species that we identified in the present study as most attractive also harboured the highest numbers of $D$. radicum eggs under natural conditions (Kergunteuil 2013). However, among the three attractive species, B. rapa pekinensis is the most stimulatory one, despite lower emissions of five compounds ( $\alpha$-pinene, limonene, $\beta$ caryophyllenne, humulene, $\alpha$-farnesene) in comparison to B. napus 'Yudal' or B. oleracea. Our results, thus, suggest that the response of cabbage root flies may also rely on quantitativequalitative changes in VOC profiles released by plants.

In our analyses, volatile blends released by undamaged plants are numerically dominated by terpenes. This class of compounds is certainly the largest group of secondary metabolites synthesized by plants (Degenhardt et al. 2009), and many olfactory receptor neurons tuned to terpenes have been identified in herbivorous insects (Bruce et al. 2005; de Bruyne and Baker 2008). Many studies report on the role played by terpene emissions induced after herbivore attacks in plant defences, but it is also recognized that constitutive release of these volatiles can directly affect the behaviour of phytophagous insects (Holopainen and Blande 2012).

As shown by principal component analysis (PCA), the VOC blends differ with plant species and genotype. However, the three levels of attractiveness observed in the olfactometer 
tests are not directly linked to three distinct groups of VOC profiles in the PCA analysis. Surprisingly, the VOC blends emitted by the two species triggering the highest differences in behavioural responses, S. alba and B. rapa pekinensis, are closely related in the PCA plot, and we cannot exclude that females respond to compounds that were not detected by our GC/MS system. Indeed, insect olfactory systems are highly sensitive, and the quality of a volatile signal can depend on compounds released at trace levels (Birkett et al. 2004). On the other hand, the set of VOCs identified allows a good separation of the volatile blends emitted by $B$. oleracea and the two genotypes of $B$. napus. These plants exhibit differences for herbivore attraction suggesting that the present study allows the identification of at least some volatiles involved in long distance orientation of the cabbage root fly.

The least attractive plants, S. alba and the 'Darmor-bzh' oilseed rape, share only three compounds: $\alpha$-pinene (3), myrcene (5) and limonene (7). Moreover, these three VOCs are also released by the other species, suggesting that no explicitly repellent compounds are released by the brassicaceous plants (i.e. the host-plant range) tested in our study. Among hundreds of compounds released by a plant, herbivores generally use only a few of them (between three and ten detectable compounds) with particular ratios in the blend to recognize host-plants (Bruce and Pickett 2011). Therefore, VOC profiles released by the least attractive plants could be characterized by an inappropriate ratio of certain volatiles or by the lack of specific compounds that are particularly important in the attraction of the cabbage root fly.

Two monoterpenes are specifically emitted by plants that were found attractive in the olfactometer: 1,8-cineole (8) and linalool (9). 1,8-Cineole has been described as toxic or repellent for various insects, but it is involved in thrips attraction (Hosseini et al. 2013; Katerinopoulos et al. 2005). Linalool plays a role in the sub-saharian "push-pull" strategy designed against stem borers: released by host-plants and trap crops, this compound is detected by the insects and stimulates oviposition. To our knowledge, the enantiomeric composition of linalool which may influence the behaviour of stem borers is unknown (Birkett et al. 2006; Khan et al. 2000; Pickett et al. 2014; but see Tamiru et al. 2011 for $(R)$ linalool affecting behaviour of natural enemies). Linalool is emitted in high amounts by the most attractive species (B. rapa pekinensis) and could be involved in the orientation of the cabbage root fly. The enantiomeric composition of the naturally produced compound should be determined (see also Reisenmann et al. 2004).

Only one sesquiterpene, $\beta$-elemene (12), is specifically emitted by an unattractive plant (B. napus 'Darmor-bzh') while four sesquiterpenes are emitted by the most attractive 
plants suggesting that some VOCs in this class of compounds may play a critical role in qualitative changes of volatile profiles. Released constitutively or induced after herbivore attack, $\alpha$-copaene (11), $\beta$-caryophyllene (13), $\alpha$-humulene (14) and $\alpha$-farnesene (15) have been previously described as compounds potentially involved in attraction of phytophagous insects to different plant species (Landolt and Guédot 2008; Magalhães et al. 2012; Robert et al. 2013; von Arx et al. 2011; Yan et al. 2003). Among these four sesquiterpenes, the release rates of $\beta$-caryophyllene (13), humulene (14) and $\alpha$-farnesene (15) observed in our results indicate that these three compounds may be important in attraction of the cabbage root fly. Unfortunately, our analytical methods did not allow to determine the stereochemistry of the identified $\alpha$-farnesene, which will be the subject of further investiations of this compound. In comparison to $S$. alba, $\beta$-caryophyllene (13) is emitted in particularly high amounts by $B$. napus 'Yudal' but also, although in lower amounts, by B. rapa pekinensis, the two most attractive plants in our olfactometer studies. Behavioural experiments with this compound would be necessary to confirm its attractiveness.

In the present study, two plants (B. napus 'Yudal' and B. rapa pekinensis) have been identified as more attractive than B. oleraceae. They could be used in the "pull" component of a "push-pull" strategy designed to protect broccoli crops. So far, only Chinese cabbage is commercialized while the 'Yudal' genotype of oilseed rape remains unavailable to farmers. Nevertheless, the characterization of the VOC profiles emitted by 'Yudal' and 'Darmor-bzh' genotypes is also interesting from the applied perspective. These two oilseed rape genotypes were recently used for investigating correlations between genetic diversity, metabolomic profiles, and susceptibility to bio-aggressors (Wagner et al. 2012). Our results extend the array of bio-aggressors for which B. napus 'Yudal' is more susceptible than the 'Darmor-bzh' genotype and suggest that these differences, concerning $D$. radicum, certainly rely on differences within plant volatile profiles. The identification of plant genome regions involved in the emission of VOC profiles altering herbivore decisions could be utilized by breeders in order to select efficient cultivars for pest behavioural-manipulation strategies. One of the main challenges in developing a "push-pull" strategy against insect pests is to keep the trap crop areas as small as possible for economic reasons. For this purpose, the attractiveness of trap crops for D. radicum could be increased with dispensers for synthetic volatiles containing linalool (9), $\beta$-caryophyllene (13), humulene (14) or $\alpha$-farnesene (15). Previous experiments carried out in broccoli plots are encouraging as they demonstrate the possibility of modifying plant infestation through the release of synthetic VOCs (Kergunteuil et al. 2012). This study, 
thus, represents a first step to identify both attractive plants species for trap crop development and additional volatiles that could be used in an effective strategy to reduce the impact of root fly damage on target crop plantations.

Acknowledgements / This study was supported by a Ph.D grant from the French Ministry for Research. Holger Danner is supported by a grant in the ESF-EuroVOL program funded by the Netherlands Organisation for Scientific Research (NWO- ALW) to NM van Dam, grant number 855.01.172. The authors gratefully acknowledge Matthias Erb and Alain Ratdnadass for their critical readings of the manuscript. 


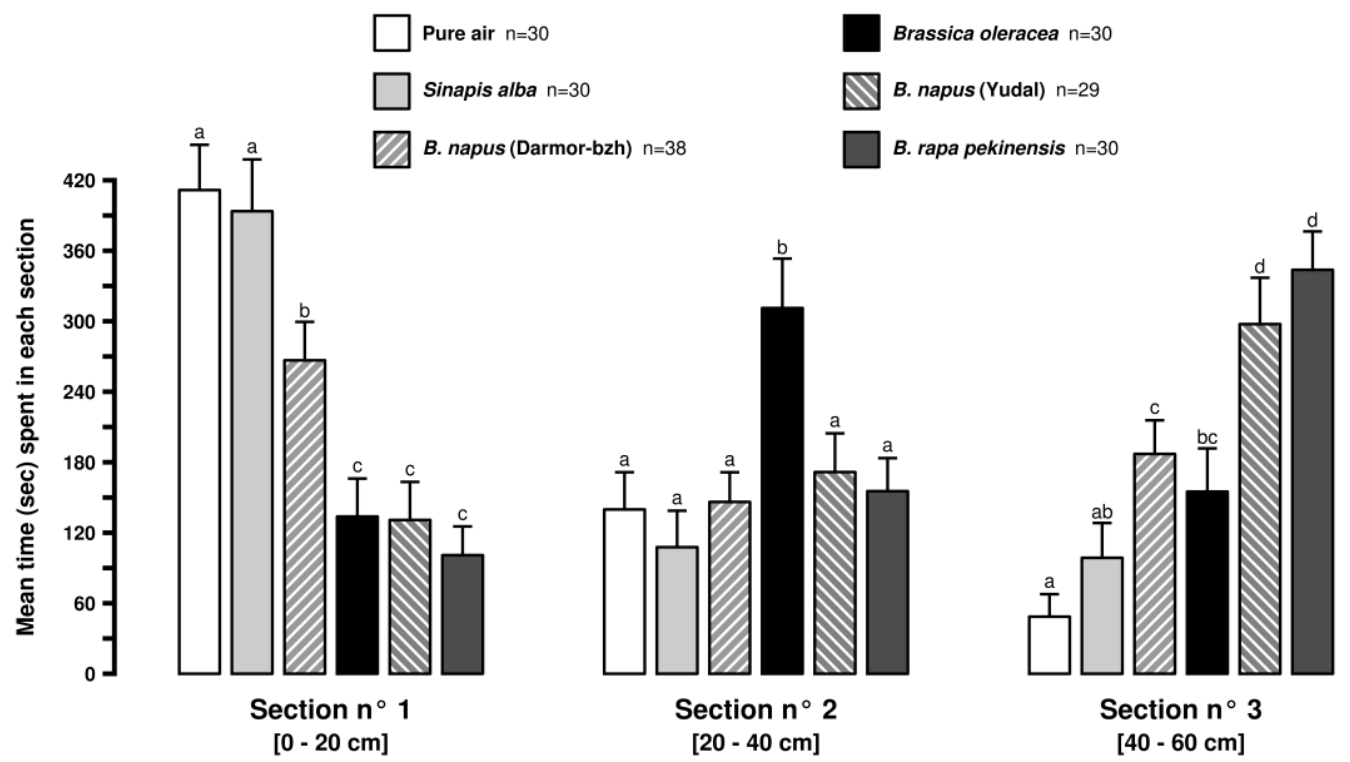

FIG. 1 Mean time in second $( \pm \mathrm{SE})$ spent by $D$. radicum females exposed to various undamaged brassicaceous plants and to pure air in a tubular olfactometer artificially divided in 3 notional sections (section $n^{\circ} 1$ : fly entrance; section $n^{\circ} 2$ : mid section; section $n^{\circ} 3$ : entrance of airflow in the tube)

Mean times were calculated after $600 \mathrm{sec}$ of observation. Significant differences in mean times are represented with different letters: GLM, contrasts method, $P<0.05$ 
Table 1 Emission of volatiles per plant (relative to internal standard \pm se) released by undamaged vegetative parts of five brassicaceous plants during $24 \mathrm{hr}$

\begin{tabular}{|c|c|c|c|c|c|c|c|c|c|}
\hline Compounds & MRI & ${ }_{\text {LRI }}^{3}$ & $\begin{array}{c}\text { Exact mass } \\
\quad(\text { amu })\end{array}$ & $\begin{array}{c}\text { Measured mass } \\
\text { (amu) }\end{array}$ & $\begin{array}{c}\text { Sinapis alba } \\
\qquad n=12\end{array}$ & $\begin{array}{c}\text { Brassica napus } \\
\text { (Darmor-bzh) } \\
n=12\end{array}$ & $\begin{array}{c}\text { B. oleracea } \\
n=12\end{array}$ & $\begin{array}{c}\text { B. napus } \\
\text { (Yudal) } \\
n=11\end{array}$ & $\begin{array}{c}\text { B. rapa } \\
\text { pekinensis } \\
n=12\end{array}$ \\
\hline 1. 1-hexanol & 865.6 & $865 a$ & 102.104 & n.d. (56-43-55-69-84) & - & - & - & $0.16 \pm 0.04$ & - \\
\hline 2. a-thujene & 927.9 & $929 \mathrm{~b}$ & 136.125 & 136.1250 & - & $0.14 \pm 0.03 a$ & $0.07 \pm 0.01 b$ & - & - \\
\hline 3. $\alpha$-pinene & 935.0 & $936 \mathrm{c}$ & 136.125 & 136.1250 & $0.20 \pm 0.05 a$ & $0.43 \pm 0.07 b$ & $1.11 \pm 0.13 c$ & $0.33 \pm 0.06 a b$ & $0.22 \pm 0.06 a$ \\
\hline 4. $\alpha$-phellandrene & 974.1 & $971 \mathrm{~d}$ & 136.125 & 136.1254 & - & $0.46 \pm 0.09 a$ & $1.85 \pm 0.32 b$ & - & - \\
\hline 5. myrcene & 993.3 & $992 \mathrm{e}$ & 136.125 & 136.1249 & $0.13 \pm 0.02 \mathrm{a}$ & $0.66 \pm 0.06 b$ & $0.25 \pm 0.04 c$ & $0.22 \pm 0.05 \mathrm{ac}$ & $1.91 \pm 0.18 \mathrm{~d}$ \\
\hline 6. hexyl acetate & 1017.7 & $1017 \mathrm{f}$ & 144.115 & n.d. (43-56-61-84-73) & - & - & - & $0.27 \pm 0.14$ & - \\
\hline 7. limonene & 1030.0 & $1029 \mathrm{~g}$ & 136.125 & 136.1253 & $1.65 \pm 0.66 \mathrm{~ns}$ & $1.88 \pm 0.59 \mathrm{~ns}$ & $3.18 \pm 0.60 \mathrm{~ns}$ & $1.64 \pm 0.51 \mathrm{~ns}$ & $1.79 \pm 0.74 \mathrm{~ns}$ \\
\hline 8. 1,8-cineole & 1032.5 & $1032 \mathrm{~b}$ & 154.136 & 154.1360 & - & - & $2.96 \pm 1.14$ & - & - \\
\hline 9. linalool & 1105.0 & $1105 \mathrm{~h}$ & 154.136 & 154.1391 & - & - & $0.17 \pm 0.04 \mathrm{a}$ & - & $6.05 \pm 0.46 b$ \\
\hline 10. nonanal & 1106.5 & $1107 \mathrm{i}$ & 142.136 & n.d. $(57-41-70-82-98)$ & - & $0.14 \pm 0.03 \mathrm{~ns}$ & - & $0.15 \pm 0.04 \mathrm{~ns}$ & - \\
\hline 12. $\beta$-elemene & 1383.5 & $1384 j$ & 204.188 & n.d. $(81-93-68-41-147)$ & - & $0.21 \pm 0.04$ & - & - & - \\
\hline 13. $\beta$-caryophyllene & 1407.7 & $1409 \mathrm{j}$ & 204.188 & 204.1890 & $0.37 \pm 0.17 \mathrm{a}$ & - & - & $26.18 \pm 0.12 b$ & $2.09 \pm 0.41 \mathrm{c}$ \\
\hline 14. humulene & 1434.8 & $1432 \mathrm{k}$ & 204.188 & 204.1884 & - & - & - & $7.15 \pm 0.12 \mathrm{a}$ & $0.53 \pm 0.12 b$ \\
\hline 15. a-farnesene & 1482.7 & $1484 \mid$ & 204.188 & 204.1877 & - & - & $7.41 \pm 1.52 \mathrm{a}$ & - & $0.24 \pm 0.04 b$ \\
\hline
\end{tabular}

For each compound, significant differences in VOCs emissions are represented with different letters: pairwise Wilcoxon rank sum tests and $P$ adjusted with the Benjamini and Hochberg correction, $P<0.05$

(1) Compounds are listed in order of their elution from a DB-5ms column

(2) MRI: measured retention indices

(3) LRI: literature retention indices taken from a) Maia et al. 2000, b) Maia et al. 2005, c) Viña and Murillo 2003, d) el Ghorab et al. 2002, e) Lucero et al. 2006, f) Fan and Qian 2006, g) Adams et al. 2005, h) Greger and Schieberle 2007, i) Chen et al. 2009, j) Santos et al. 2004, k) Marongiu et al. 2003, 1) Marongiu et al. 2001

(4) n.d. : molecular peak not detected, typical mass fragments in order of intensity are indicated between brackets. For compounds released by more than one of the five plants tested, exact masses are calculated by averaging the masses recorded for individual plants of each cultivar resp. species 


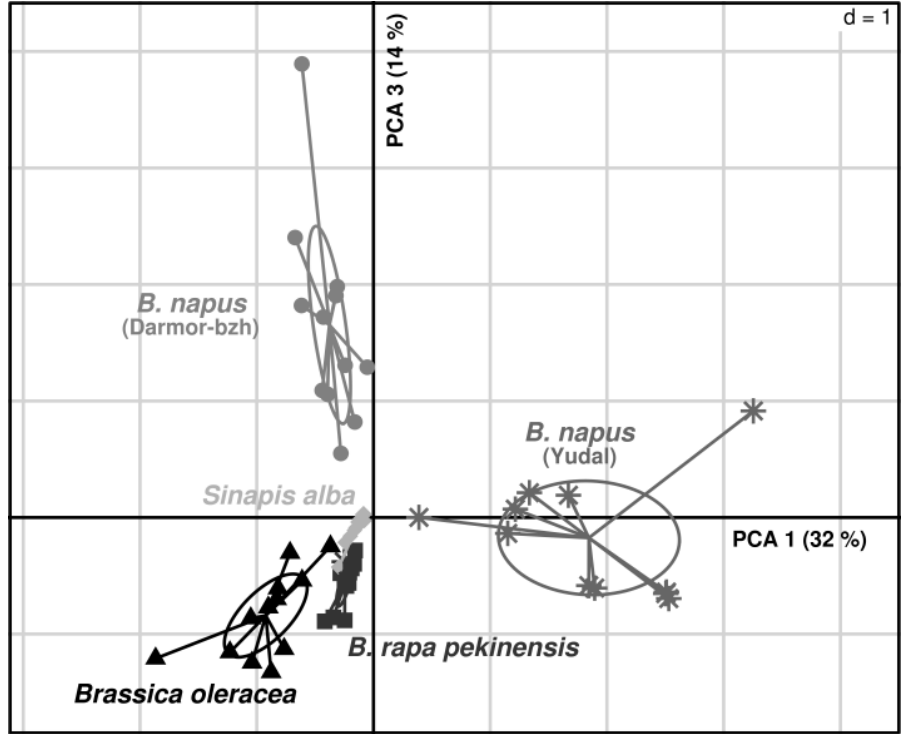

(a)

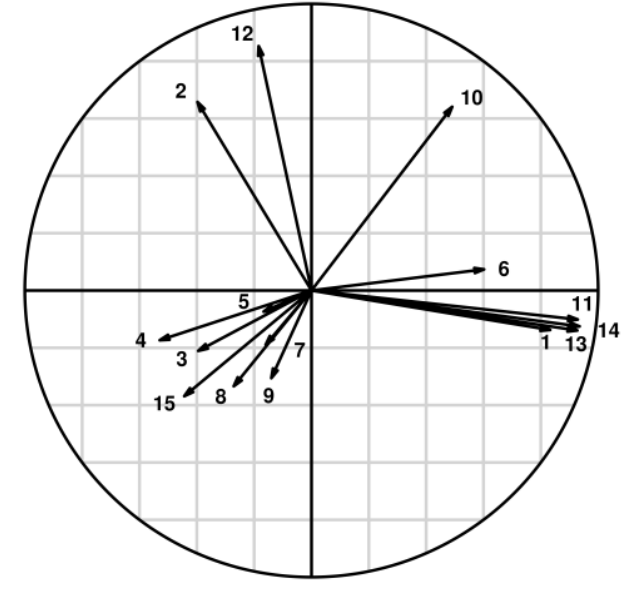

(b)

FIG. 2 Multivariate analysis of volatiles collected from undamaged vegetative parts of five brassicaceous plants

(a) Principal component analysis (PCA) of volatile organic compounds released during 24hr. The percentage of explained variance for each axis of the PCA appears in parentheses (b) Correlation circle of the PCA. The correlation circle represents the direction and intensity of correlation of original variables with the two axis of the PCA. The numbers presented on the graphic correspond to: 1-hexanol (1), $\alpha$-thujene (2), $\alpha$-pinene (3), $\alpha$-phellandrene (4), myrcene (5), hexyl acetate (6), limonene (7), 1,8-cineole (8), linalool (9), nonanal (10), $\alpha$ copaene (11), $\beta$-elemene (12), $\beta$-caryophyllene (13), humulene (14) and $\alpha$-farnesene (15) 


\section{REFERENCES}

Abel C, Clauss M, Schaub A, Gershenzon J, Tholl D (2009) Floral and insect-induced volatile formation in Arabidopsis lyrata spp. petrea, a perennial, outcrossing relative of A. thaliana. Planta 230:1-11

Adams RP, Morris JA, Pandey RN, Schwarzbach AE (2005) Cryptic speciation between Juniperus deltoides and Juniperus oxycedrus (Cupressaceae) in the Mediterranean. Biochem Syst Ecol 33:771-787

Bates D, Maechler M, Bolker B (2013) lme4: Linear mixed-effects models using S4 classes. R package version 0.999999-2. http://CRAN.R-project.org/package=lme4

Bengtsson M, Bäckman AC, Liblikas I, Ramirez MI, Borg-Karlson AK, Ansebo L, Anderson P, Löfqvist J, Witzgall P (2001) Plant odor analysis of apple: antennal response of codling moth females to apple volatiles during phenological development. J Agr Food Chem 49:37363741

Benjamini Y, Hochberg Y (1995) Controlling the false discovery rate: a practical and powerful approach to multiple testing. J Roy Stat Soc B 57:289-300

Birkett MA, Bruce TJA, Martin JL, Smart LE, Oakley JON, Wadhams LJ (2004) Responses of female orange wheat blossom midge, Sitoplosis mosellana, to wheat panicle volatiles. J Chem Ecol 30:1319-1328

Birkett MA, Chamberlain K, Khan ZR, Pickett JA, Toshova T, Wadhams LJ, Woodcock CM (2006) Electrophysiological responses of the lepidopterous stemborers Chilo partellus and Busseola fusca to volatiles from wild and cultivated host plants. J Chem Ecol 32:2475-2487

Bruce TJA, Pickett JA (2011) Perception of plant volatile blends by herbivorous insects Finding the right mix. Phytochemistry 72:1605-1611

Bruce TJA, Wadhams LJ, Woodcock CM (2005) Insect host location: a volatile situation. Trends Plant Sci 10:269-274

Chen G, Song H, Ma C (2009) Aroma-active compounds of Beijing roast duck. Flavour Frag J 24:186-191

Cook SM, Khan ZR, Pickett JA (2007 a) The use of push-pull strategies in integrated pest management. Annu Rev Entomol 52:375-400 
Cook SM, Rasmussen HB, Birkett MA, Murray DA, Pye BJ, Watts NP, Williams IH (2007 b) Behavioural and chemical ecology underlying the success of turnip rape (Brassica rapa) trap crops in protecting oilseed rape (Brassica napus) from the pollen beetle (Meligethes aenus). Arthropod Plant Interact 1:57-67

de Bruyne M, Baker TC (2008) Odor detection in insects: volatile codes. J Chem Ecol $34: 882-897$

Degenhardt J, Köllner TG, Gershenzon J (2009) Monoterpene and sesquiterpene synthases and the origin of terpene skeletal diversity in plants. Phytochemistry 70:1621-1637

de Jong R, Maher N, Patrian B, Städler E, Winkler T (2000) Rutabaga roots, a rich source of oviposition stimulants for the cabbage root fly. Chemoecology 10:205-209

Delourme R, Piel N, Horvais R, Pouilly N, Domin C, Vallée P, Falentin C, ManzanaresDauleux MJ, Renard M (2008) Molecular and phenotypic characterization of near isogenic lines at QTL for quantitative resistance to Leptosphaeria maculans in oilseed rape (Brassica napus L.). Theor Appl Genet 117:1055-1067

den Ouden H, Alkema DPW, Klijnstra JW, Theunissen J, de Vlieger JJ (1997) Preference and non-preference experiments with aerial repellents against Delia radicum L. (Dipt., Anthomyiidae) in a wind tunnel. J Appl Entomol 121:275-279

Dicke M, Baldwin IT (2010) The evolutionary context for herbivore-induced plant volatiles: beyond the 'cry for help'. Trends Plant Sci 15:167-175

Dray S, Dufour AB (2007) The ade4 package: implementing the duality diagram for ecologists. J Stat Softw 22:1-20

el Ghorab AH, Fadel HM, el Massry KF (2002) The egyptian Eucalyptus camaldulensis var. brevirostris: chemical compositions of the fruit volatile oil and antioxidant activity. Flavour Frag J 17:306-312

Fan W, Qian MC (2006) Identification of aroma compounds in Chinese "Yanghe Daqu" liquor by normal phase chromatography fractionation followed by gas chromatography / olfactometry. Flavour Frag J 21:333-342

Ferry A, Le Tron S, Dugravot S, Cortesero AM (2009) Field evaluation of the combined deterrent and attractive effects of dimethyl disulfide on Delia radicum and its natural enemies. Biol Control 49:219-226 
Finch S (1989) Ecological considerations in the management of Delia pest species in vegetable crops. Annu Rev Entomol 34:117-137

Finch S, Collier RH (2000) Host-plant selection by insects - a theory based on 'appropriate/inappropriate landings' by pest insects of cruciferous plants. Entomol Exp Appl 96:91-102

Finch S, Skinner G (1982) Upwind flight by the cabbage root fly, Delia radicum. Physiol Entomol 7:387-399

Gols R, Veenemans C, Potting RPJ, Smid HM, Dicke M, Harvey JA, Bukovinszky T (2012) Variation in the specificity of plant volatiles and their use by a specialist and a generalist parasitoid. Anim Behav 83:1231-1242

Greger V, Schieberle P (2007) Characterization of the key aroma compounds in apricots (Prunus armeniaca) by application of the molecular sensory science concept. J Agr Food Chem 55:5221-5228

Griffiths DW, Deighton N, Birch ANE, Patrian B, Baur R, Städler E (2001) Identification of glucosinolates on the leaf surface of plants from the Cruciferae and other closely related species. Phytochemistry 57:693-700

Halitschke R, Stenberg JA, Kessler D, Kessler A, Baldwin IT (2008) Shared signals -'alarm calls' from plants increase apparency to herbivores and their enemies in nature. Ecol Lett $11: 24-34$

Hawkes C, Coaker TH (1979) Factors affetring the behavioural responses of the adult cabbage root fly, Delia brassicae, to host plant odour. Entomol Exp Appl 25:45-58

Højsgaard S, Halekoh U, Robison-Cox J, Wright K, Leidi AA (2013) doBy: doBy Groupwise summary statistics, general linear contrasts, population means (least-squaresmeans), and other utilities. $\mathrm{R}$ package version 4.5-6. http://CRAN.Rproject.org/package $=$ doBy

Holopainen JK, Blande JD (2012) Molecular plant volatile communication. In: Lopez-Larrea C (ed) Sensing in nature. Landes bioscience and Springer science, New York, pp. 17-31

Hosseini B, Estaji A, Hashemi SM (2013) Fumigant toxicity of essential oil from Salvia leriifolia (Benth) against two stored product insect pests. Aust J Crop Sci 7:855-860

Ibrahim MA, Nissinen A, Holopainen JK (2005) Response of Plutella xylostella and its parasitoid Cotesia plutellae to volatile compounds. J Chem Ecol 31:1969-1984 
Jestin C, Lodé M, Vallée P, Domin C, Falentin C, Horvais R, Coedel S, Manzanares-Dauleux MJ, Delourme R (2011) Association mapping of quantitative resistance for Leptosphaeria maculans in oilseed rape (Brassica napus L.). Mol Breeding 27:271-287

Jyoti JL, Shelton AM, Earle ED (2001) Identifying sources and mechanisms of resistance in crucifers for control of cabbage maggot (Diptera: Anthomoyiidae). J Econ Entomol 94:942$\underline{949}$

Katerinopoulos HE, Pagona G, Afratis A, Stratigakis N, Roditakis N (2005) Composition and insect attracting activity of the essential oil of Rosmarinus officinalis. J Chem Ecol 31:111122

Kergunteuil A (2013) Des odeurs pour protéger les cultures : utilisation de composés volatils pour modifier le comportement de la mouche du chou, Delia radicum, et de ses ennemis naturels. PhD Thesis, Rennes1 university, France

Kergunteuil A, Dugravot S, Mortreuil A, Le Ralec A, Cortesero AM (2012) Selecting volatiles to protect brassicaceous crops against the cabbage root fly, Delia radicum. Entomol Exp Appl 144:69-77

Khan ZR, Midega CAO, Bruce TJA, Hooper AM, Pickett JA (2010) Exploiting phytochemicals for developing a "push-pull" crop protection strategy for cereal farmers in Africa. J Exp Bot 61:4185-4196

Khan ZR, Midega CAO, Pittchar JO, Murage AW, Birkett MA, Bruce JA, Pickett JA (2014) Achieving food security for one million sub-Saharan African poor through push - pull innovation by 2020. Phil Trans R Soc B 369: 20120284

Khan ZR, Pickett JA, van den Berg J, Wadhams LJ, Woodcock CM (2000) Exploiting chemical ecology and species diversity: stem borer and striga control for maize and sorghum in Africa. Pest Manag Sci 56:957-962

Kuhl C, Tautenhahn R, Boettcher C, Larson TR, Neumann, S (2012) CAMERA: an integrated strategy for compound spectra extraction and annotation of liquid chromatography/mass spectrometry data sets. Anal Chem 84:283-289

Landolt PJ, Guédot C (2008) Field attraction of codling moths (Lepidoptera: Tortricidae) to apple and pear fruit, and quantitation of kairomones from attractive fruit. Ann Entomol Soc Am 101:675-681 
Lucero ME, Fredrickson EL, Estell RE, Morrison AA, Richman DB (2006) Volatile composition of Gutierrezia sarothrae (Broom Snakeweed) as determined by steam distillation and solid phase microextraction. J Essent Oil Res 18:121-125

Magalhaes DM, Borges M, Laumann RA, Sujii ER, Mayon P, Caulfield JC, Midega CAO, Khan ZR, Pickett JA, Birkett MA, Blassioli-Moraes MC (2012) Semiochemicals from herbivory induced cotton plants enhance the foraging behavior of the cotton boll weevil, Anthonomus grandis. J Chem Ecol 38:1528-1538

Maia JGS, Andrade EHA, da Silva ACM, Oliveira J, Carreira LMM, Araújo JS (2005) Leaf volatile oils from four Brazilian Xylopia species. Flavour Frag J 20:474-477

Maia JGS, Andrade EHA, Zoghbi MGB (2000) Volatile constituents of the leaves, fruits and flowers of cashew (Anacardium occidentale L.). J Food Comp Anal 13:227-232

Manzanares-Dauleux MJ, Delourme R, Baron F, Thomas G (2000) Mapping of one major gene and of QTLs involved in resistance to clubroot in Brassica napus. Theor Appl Genet $101: 885-891$

Marongiu B, Piras A, Pani F, Porcedda S, Ballero M (2003) Extraction, separation and isolation of essential oils from natural matrices by supercritical CO2. Flavour Frag J 18:505509

Marongiu B, Porcedda S, Porta GD, Reverchon E (2001) Extraction and isolation of Salvia desoleana and Mentha spicata subsp. insularis essential oils by supercritical CO2. Flavour Frag J 16:384-388

Neveu Bernard-Griffiths N (1998) Sélection de l'hôte chez Trybliographa rapae W. (Hymenoptera: Figitidae), parasitoïde de la mouche du chou Delia radicum L. (Diptera: Anthomyiidae) ; perspectives d'application en lutte biologique. PhD Thesis, Rennes1 university, France

Pickett JA, Aradottir GI, Birkett MA, Bruce TJA, Chamberlain K, Khan ZR, Midega CAO, Smart LE, Woodcock CM (2012) Aspects of insect chemical ecology: exploitation of reception and detection as tools for deception of pests and beneficial insects. Physiol Entomol $37: 2-9$

Pickett JA, Woodcock CM, Midega CAO, Khan ZR (2014) Push-pull farming systems. Curr Opin Biotech 26:125-132 
Pierre PS, Jansen JJ, Hordijk CA, van Dam NM, Cortesero AM, Dugravot S (2011) Differences in volatile profiles of turnip plants subjected to single and dual herbivory aboveand belowground. J Chem Ecol 37:368-377

Piesik D, Pańka D, Jeske M, Wenda-Piesik A, Delaney KJ, Weaver DK (2013) Volatile induction of infected and neighbouring uninfected plants potentially influence attraction/repellence of a cereal herbivore. J Appl Entomol 137:296-309

R Core Team (2014) R: A language and environment for statistical computing. R Foundation for Statistical Computing, Vienna, Austria. http://www.R-project.org/

Reisenman CS, Christensen TA, Francke W, Hildebrand JG (2004) Enantioselectivity of projection neurons innervating identified olfactory glomeruli. J Neurosci 24:2602-2611

Robert CAM, Erb M, Hiltpold I, Hibbard BE, Gaillard MDP, Bilat J, Degenhardt J, CambetPetit-Jean X, Turlings TCJ, Zwahlen C (2013) Genetically engineered maize plants reveal distinct costs and benefits of constitutive volatile emissions in the field. Plant Biotechnol J 11:628-639

Roessingh P, Städler E (1990) Foliar form, colour and surface characteristics influence oviposition behaviour in the cabbage root fly Delia radicum. Entomol Exp Appl 57:93-100

$\underline{\text { Rousse P, Fournet S, Porteneuve C, Brunel E (2003) Trap cropping to control Delia radicum }}$ populations in cruciferous crops: first results and future applications. Entomol Exp Appl 109:133-138

Sabelis M, Janssen A, Kant MR (2001) The enemy of my enemy is my ally. Science 291:2104-2105

Santos AP, Lopes MC, Limberger RP, Apel MA, Henriques AT, Moreno PRH (2004) Analysis of the volatile oil from Pilocarpus pennatifolius Lemmaire (Rutaceae) leaves by GC-MS. Flavour Frag J 19:325-326

Schiestl FP (2010) The evolution of floral scent and insect chemical communication. Ecol Lett 13:643-656

Schoonhoven LM, van Loon JJA, Dicke M (2005) Insect-Plant Biology, $2^{\text {nd }}$ edn. Oxford University Press, UK

Shrivastava G, Rogers M, Wszelaki A, Panthee DR, Chen F (2010) Plant volatiles-based insect pest management in organic farming. Crit Rev Plant Sci 29:123-133 
Smith CA, Want EJ, O’Maille G, Abagyan R, Siuzdak G (2006) XCMS: processing mass spectrometry data for metabolite profiling using nonlinear peak alignment, matching, and identification. Anal Chem 78:779-787

Szendrei Z, Rodriguez-Saona C (2010) A meta-analysis of insect pest behavioral manipulation with plant volatiles. Entomol Exp Appl 134:201-210

Tamiru A, Bruce TJA, Woodcock CM, Caulfield JC, Midega CAO, Ogol C K, Mayon P, Birkett MA, Pickett JA, Khan Z R (2011) Maize landraces recruit egg and larval parasitoids in response to egg deposition by a herbivore. Ecol Lett 14:1075-1083

Tholl D, Boland W, Hansel A, Loreto F, Röse USR, Schnitzler JP (2006) Practical approaches to plant volatile analysis. Plant J 45:540-560

Togni PHB, Laumann RA, Medeiros MA, Sujii ER (2010) Odour masking of tomato volatiles by coria L, Bergström G (1988) Headspace volatiles of whole plants and macerated plant parts of Brassica and Sinapis. Entomol Exp Appl 136:164-173

Tollsten L, Bergström G (1989) Headspace volatiles of whole plants and macerated plant parts of Brassica and Sinapis. Phytochemistry 27:4013-4018

Tuttle AF, Ferro DN, Idoine K (1988) Role of visual and olfactory stimuli in host fonding of adult cabbage root flies, Delia radicum. Entomol Exp Appl 47:37-44

van Dam NM, Qiu B, Hordijk CA (2010) Identification of biologically relevant compounds in aboveground and belowground induced volatile blends. J Chem Ecol 36:1006-1016

Viña A, Murillo E (2003) Essential oil composition from twelve varieties of basil (Ocimum spp) grown in Colombia. J Braz Chem Soc 14:744-749

Visser H (1986) Host odor perception in phytophagous insects. Annu Rev Entomol 31:121144.

von Arx M, Schmidt-Büsser D, Guerin PM (2011) Host plant volatiles induce oriented flight behaviour in male European grapevine moths, Lobesia botrana. J Insect Physiol 57:13231331

Wagner G, Charton S, Lariagon C, Laperche A, Lugan R, Hopkins J, Frendo P, Bouchereau A, Delourme R, Gravot A, Manzanares-Dauleux MJ (2012) Metabotyping: a new approach to investigate rapeseed (Brassica napus L.) genetic diversity in the metabolic response to clubroot infection. Mol Plant Microbe In 25:1478-1491 
Wallbank BE, Wheatley GA (1979) Some responses of cabbage root fly (Delia brassicae) to allyl isothiocyanate and other volatile constituents of crucifers. Ann Appl Biol 91:1-12

Wang H, Guo WF, Zhang PJ, Wu ZY, Liu SS (2008) Experience-induced habituation and preference towards non-host plant odors in ovipositing females of a moth. J Chem Ecol 34:330-338

Yan F, Bengtsson M, Makranczy G, Löfqvist J (2003) Roles of alpha-farnesene in the behaviors of codling moth females. Zestschrift für naturforschung C 58:113-118nder volatiles in host plant selection of Bemisia tabaci biotype B. Entomol Exp Appl 136:164-173

Zhang ZQ, Sun XL, Xin ZJ, Luo ZX, Gao Y, Bian L, Chen ZM (2013) Identification and field evaluation of non-host volatiles disturbing host location by the tea geometrid, Ectropis 